\title{
Expression profiling of prospero in the Drosophila larval chemosensory organ: Between growth and outgrowth
}

\author{
Laure Guenin ${ }^{1,2}$, Mahatsangy Raharijaona ${ }^{3,4}$, Rémi Houlgatte ${ }^{3,4}$, Fawzia Baba-Aissa ${ }^{2 *}$
}

\begin{abstract}
Background: The antenno-maxilary complex (AMC) forms the chemosensory system of the Drosophila larva and is involved in gustatory and olfactory perception. We have previously shown that a mutant allele of the homeodomain transcription factor Prospero (prosVoila1, V1), presents several developmental defects including abnormal growth and altered taste responses. In addition, many neural tracts connecting the AMC to the central nervous system (CNS) were affected. Our earlier reports on larval AMC did not argue in favour of a role of pros in cell fate decision, but strongly suggested that pros could be involved in the control of other aspect of neuronal development. In order to identify these functions, we used microarray analysis of larval AMC and CNS tissue isolated from the wild type, and three other previously characterised prospero alleles, including the V1 mutant, considered as a null allele for the AMC.

Results: A total of 17 samples were first analysed with hierarchical clustering. To determine those genes affected by loss of pros function, we calculated a discriminating score reflecting the differential expression between V1 mutant and other pros alleles. We identified a total of 64 genes in the AMC. Additional manual annotation using all the computed information on the attributed role of these genes in the Drosophila larvae nervous system, enabled us to identify one functional category of potential Prospero target genes known to be involved in neurite outgrowth, synaptic transmission and more specifically in neuronal connectivity remodelling. The second category of genes found to be differentially expressed between the null mutant AMC and the other alleles concerned the development of the sensory organs and more particularly the larval olfactory system. Surprisingly, a third category emerged from our analyses and suggests an association of pros with the genes that regulate autophagy, growth and insulin pathways. Interestingly, EGFR and Notch pathways were represented in all of these three functional categories. We now propose that Pros could perform all of these different functions through the modulation of these two antagonistic and synergic pathways.
\end{abstract}

Conclusions: The current data contribute to the clarification of the prospero function in the larval AMC and show that pros regulates different function in larvae as compared to those controlled by this gene in embryos. In the future, the possible mechanism by which Pros could achieve its function in the AMC will be explored in detail.

\section{Background}

In Drosophila, some external sensory organs found in the anterior region of larvae are composed of many neurons and support cells that seem to represent an aggregation of several sensory units. This is the case for the antenno-maxillary complex (AMC) that forms the

\footnotetext{
* Correspondence: fawzia.baba-aissa@u-bourgogne.fr

²Université de Bourgogne, Facultés des Sciences, Unité Mixte de Recherche 5548 Associée au Centre National de la Recherche Scientifique, 6, Bd Gabriel, 21000 Dijon, France
}

(c) 2010 Guenin et al; licensee BioMed Central Ltd. This is an Open Access article distributed under the terms of the Creative Commons Attribution License (http://creativecommons.org/licenses/by/2.0), which permits unrestricted use, distribution, and reproduction in any medium, provided the original work is properly cited. chemosensory system of the Drosophila larva. The chemosensory apparatus of the larval head is formed during embryogenesis [1] and consists essentially of three major sensilla complexes on the cephalic lobe, the dorsal (DO), terminal (TO) and ventral organs (VO), and a series of pharyngeal sensilla $[2,3]$. While the DO appears to be a mixed smell and taste organ, the TO, VO and pharyngeal sensilla may be exclusively gustatory [4-7].

In previous studies, we described a mutant allele of the transcription factor prospero (Voila1, V1) that is 
associated with several alterations in both AMC and the CNS [8]. V1 homozygotes die before forming pupae. Surviving larvae remain much smaller than wild-type individuals and are impaired for their response to salt and sucrose [9]. Using a set of previously characterised Voila alleles (pros V) that express different levels of Prospero (Pros) protein, we found that the level of Pros expression detected in the embryonic precursor region of the $\mathrm{AMC}$, was related to the degree of alteration of larval taste [10]. In embryonic and larval AMC, Pros is expressed in the same cell cluster ( $\sim 50$ cells), including neuronal cells $(\sim 10$ cells) and many accessory cells but no glial cells [8].

The pros gene encodes a transcription factor protein that contains a highly divergent putative homeodomain and a conserved Prospero domain that are both necessary for sequence-specific DNA binding and Prospero nuclear localisation [11-13]. Pros is known to be expressed in neuronal precursor cells $[14,15]$ and participates in cell fate decision in both neuroblasts and sensory organ lineages [16-19]. Pros has been shown to control axonal and dendritic outgrowth [15], glial development [20,21] and to be a key regulator of mitotic activity in embryos [22]. Pros affects several cell cycle genes and can either promote or inhibit them depending on the cellular or the developmental context [23,24]. More recently Choksi et al. [25] showed that in the embryonic nerve cord Pros repressed target genes such as cell cycle genes required for self-renewal, and was also required to activate genes involved in terminal differentiation.

In a previous study on the larval antenno-maxillary complex, we showed that loss of pros function did not alter the mitotic activity or the final number of neurons. By contrast, many neural tracts connecting the AMC to the CNS are affected [8]. Therefore, it is possible that one key role of Pros in the larval AMC is to control the expression of genes involved in neuron-specific development such as axon routing and/or neurite outgrowth. However, as Pros is expressed in non-neuronal cells in the AMC (accessory cells), it is likely that, it regulates genes that are also involved in other functions.

In order to identify the Pros target genes associated with this organ, we performed microarray analysis on larval AMC tissue isolated from the wild type, the $V 1$ mutant and two previously characterised prospero alleles [8], V13 (prosVoila13) and V24 (prosVoila24, see also Table 1). To establish the AMC specificity of these genes, we included analysis of samples from isolated larval CNS for these four alleles.

Our findings indicate that, in this sensory organ, pros is mainly associated with the regulation of genes that are essential for correct routing of neural processes and synaptic transmission. Many of these genes are involved in the development and remodelling of the nervous system during metamorphosis. Interestingly, we also found that loss of pros function induced the misregulation of a subset of genes important for growth, and autophagy. Finally, the possible role of EGFR (the epidermal growth factor receptor) and the $N$ (Notch) pathway in regulating all of these functions is discussed.

\section{Results}

\section{The developing AMC and Pros expression}

We have previously shown [8] that in the developing AMC, Pros is always expressed in the same cluster of cells. In addition, neither mitotic activity nor apoptosis was observed during the third instar larval stage or at late embryonic stages suggesting that the final number of Pros expressing cells is fixed before the end of embryogenesis [8]. This hypothesis was further confirmed by analysing mitotic activity in the developing wild type AMC (prosVoila14, V14) using an H3p marker. Our results showed that the H3p labelling disappeared completely after the embryonic stages 12-13 [Additional file 1] indicating that additional cells are not provided until the last larval stage. However, some Pros expressing cells grew in size at the LIII stage. Scoring the different Pros + cell type morphology (Figure 1, Table 2), we found that the wild type larval AMC (TO and DO) was composed of $8( \pm 1)$ large Pros + cells (most probably accessory cells) and $40( \pm 4.1)$ small Pros+ cells. Among the latter, $10.7( \pm 2.8)$ were neuronal cells [8]. Pros is never expressed in glial cells. Interestingly, pros loss of function affected the axonal pathway in the embryonic AMC, but produced the correct number of neuronal cells [8] and curiously induced an excess of glial cells, which, we suspect, originated from incorrect peripheral glial cells migration. Therefore, if Pros was expressed in the same number of cells in the embryo and larvae and since no additional cell division was seen after stage 13, it is likely that pros is not involved in cell fate choice in the larval AMC.

To better clarify the role of pros in the AMC, we carried out microarray analysis on wild type (V14) and three prospero mutants (V1, V13, V24, see also Table 1), which present different expression levels of Pros $[8,10]$. $V 1$ is considered as a null pros allele for the larval AMC as no Pros protein is detected in this organ. It presents an abnormal taste response to sucrose and $\mathrm{NaCl}$ (indifferent to both substances), and shows an alteration of the neural connections between the AMC and CNS as well as arborisation defects in larval neuromuscular junction [10]. In the V1 larval CNS, Pros is still expressed but at a lower level than in the wild type V14. $V 1$ larval CNS also shows several defects, which include early initiation of cell death and abnormal sub-cellular localization of the Pros protein [Additional file 2: supplemental figure A]. 
Table 1 Overview of the phenotypes associated with the different prosV alleles.

\begin{tabular}{|c|c|c|c|c|c|c|}
\hline Allele & Genotype & Stage of lethality & $\begin{array}{l}\text { Larval taste } \\
\text { response }\end{array}$ & $\begin{array}{c}\text { Pros expression in } \\
\text { AMC } \\
\end{array}$ & $\begin{array}{l}\text { Pros expression } \\
\text { in CNS }\end{array}$ & $\begin{array}{c}\text { Axonal routing in } \\
\text { AMC } \\
\end{array}$ \\
\hline V14 & $\begin{array}{l}\text { Wild type (complete PGal4 } \\
\text { remobilization) }\end{array}$ & Viable & Normal & Normal & Normal & Normal \\
\hline V13 & $\begin{array}{l}\text { Partial pGal4 excision (remaining } \\
\text { of } 718 \mathrm{bp} \text { ) }\end{array}$ & $\begin{array}{l}\text { Young adult }<2 \\
\text { days old }\end{array}$ & Normal & Normal & altered & Normal \\
\hline V24 & $\begin{array}{c}\text { Partial pGal4 excision (remaining } \\
\text { of } 7400 \mathrm{pb} \text { ) }\end{array}$ & pupal & Intermediate & Normal & altered & Normal \\
\hline$V 1$ & $\begin{array}{l}\text { full length pGal4 transposon } \\
\text { (12900 pb) }\end{array}$ & larva & Altered & absent & altered & Misrouting \\
\hline
\end{tabular}

(redrawn from Guenin et al. [8]).

In the prosV1 (V1) allele, the full length PGal4 transposon is inserted upstream of the pros coding region (-216 bp). prosV14 (V14) results from the correct and total remobilization of the transposon, in this strain the wild type phenotype is restored. In prosV24 (V24) and prosV13 (V13), the PGal4 element has been partially removed, respectively 7400 and 718 bp remain inserted $216 \mathrm{bp}$ upstream the pros start site. The peak of developmental lethality, the taste response of late homozygous 2nd instar larva, Pros expression level in larvae and axonal misrouting are indicated for each pros $V$ allele.

The larval taste response was measured towards $0.1 \mathrm{M}$ sucrose and $0.3 \mathrm{M} \mathrm{NaCl}$ concentration that are known to respectively attract or repulse wild type Drosophila. V1 mutants were indifferent to both substances (altered taste response), V24 showed an intermediate response: they were repulsed by NaCl but remained indifferent to sucrose and V13 and V14 present a normal taste response to both substances. The Pros expression pattern is indicated by comparison to the V14 wild type: In the AMC, V1 showed no Pros expression but for the other alleles, Pros expression pattern was similar to V14. In the CNS, all mutant alleles showed a distinct altered expression pattern as compared to the wild type (further descriptions of the Pros pattern are found in the text and in [Additional file 2]).

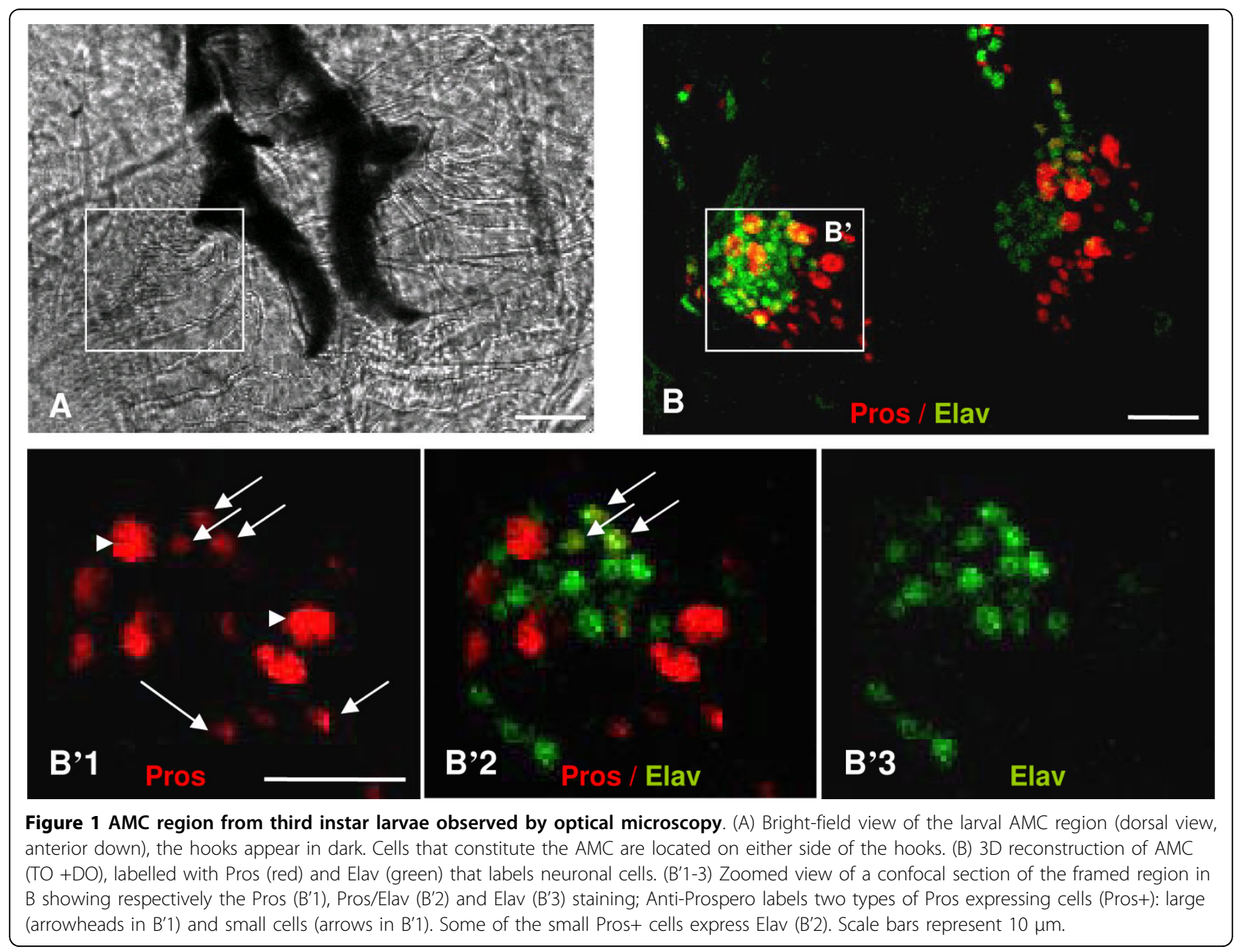


Table 2 Pros expressing cells in the larval AMC

\begin{tabular}{lllll}
\hline Cell types & Large cells & Small cells & & \\
\hline Alleles & Pros+ & Pros + & Pros+/Elav+ & Elav+ \\
\hline V14 & $8^{* 1}$ & $40.9 \pm 4.1$ & $10.7 \pm 2.8$ & $65.8 \pm 1.4$ \\
\hline V1 & $0^{* * *}$ & $0^{* * *}$ & $0^{* * *}$ & $62.3 \pm 0.9$ \\
\hline
\end{tabular}

We have quantified the number of Pros expressing cells (Pros+) and neuronal cells (Elav+) in the third instar larval AMC of wild type (V14) and V1 mutants. We distinguish two types of Pros+ cells on the basis of their size: large and small cells. Some small Pros+ cells express Elav markers and are probably differentiated neurons. In V1 mutants, no more Pros protein is detected in the larval AMC, but the number of neurons remains unchanged.

$V 13$ and $V 24$ are both derived from the $V 1$ allele and result from incomplete excision of the PGal4 transposon, respectively 7400 and 718 bp remain inserted upstream of the pros start site (see also Table 1). A previous study showed that V13 [8] and V24 (Personal communication) present a correct structure of the larval AMC and a normal expression level of pros mRNA. No variation was observed in the number of glia or neuron cells and the pattern of Pros expression was similar to that of the wild type V14. Since, V14, V24 and V13 present the same expression pattern in the AMC and have the same genetic background, individual variations (independent of Pros expression), can be more easily eliminated by the use of several but similar fly lines.

In the CNS both alleles overexpress (at different levels) the pros mRNA but present a distinct pattern as regards to the mitotic activity or to the Pros and Elav (neuronal cells marker) labelling [Additional file 2]. In the ventral nerve cord $V 13$ showed a clear hyperplasia due to an excess of neurons [Additional file 2: supplemental figure B]. Finally, mitotic activity, revealed by anti-pHistone-H3 antibody (H3p) [Additional file 2: supplemental figure C] was strongly increased, especially in the Optic Lobes of $V 24$. In conclusion, each of $V 24$ and $V 13$ allele presented a distinct abnormal pattern as compared to the wild type V14. Therefore, we used in the CNS V13 allele only as its Pros expression pattern was previously published.

All these alleles were used to for the transcriptome analysis since they have the same genetic background.

Most specifically, to identify the genes that are misregulated in the AMC, the comparison was made between the null AMC V1 mutant and the other alleles $V 14$, $V 24, V 13$ as all three present the same wild type expression pattern in this structure.

It should be mentioned that the role of Pros in the larvae CNS was not investigated in this study. The CNS was used to be compared with AMC (for this only V14, $V 1$ and $V 13$ alleles were selected) and to determine whether the putative candidate genes identified in the AMC could be found in the CNS. For this latest purpose, we decided to limit the microarray analysis in the CNS to the comparison between $V 14$ and $V 1$, since the
$V 13$ allele presents an intermediate Pros expression pattern in the CNS. This avoids misinterpretation of the CNS data.

\section{Transcription profile of prosV1 larvae}

Expression data of a total of 17 samples were analysed, including both CNS and AMC samples for the four pros $V$ alleles and 2 to 3 independent RNA extractions for each allele. We searched for sets of genes participating in the same biological function (with correlated expression) and differentially expressed between pros $V$ mutants. We used the Discriminating Score (DS, see also Methods section) as the detection method for differential expression, smoothed on the hierarchical clustering tree to detect peaks of correlated genes. This method had the advantage of detecting peaks of optimal size. This size could not be known a priori. A DS score can be assigned to each node in the dendrogram. The node corresponding to the maximum DS score was chosen as the node best fitting the peak.

The results were displayed using TreeView [26]. As it can be seen in the Figure 2A, a cluster of genes differentially expressed in AMC and CNS tissues and in a Pros independent manner was observed. The genes of this cluster (AMC tissue specific signature) were clearly overexpressed in the AMC while the same genes were underexpressed for all alleles in the CNS (Figure 2A).

In the next step, we determined those genes affected by loss of pros function for each organ with the DS. For the AMC, as V13, V14 and V24 have a normal Pros expression pattern in this structure, the DS was calculated for each gene between $V 1$ and all other alleles. For the CNS, since $V 13$ exhibited a distinct pattern [Additional file 2], the DS for each gene was calculated between $V 1$ and the $V 14$ alleles only.

To visualize groups of correlated genes that were differentially expressed between $V 1$ and other alleles, the DS score obtained for the AMC or CNS was plotted alongside the hierarchical clustering and smoothed in a sliding windows of 100 genes. As shown in Figure 2B, different peaks can be detected. Each peak represents co-expressed genes sensitive to Pros expression. To avoid the analysis of non-significant variations, we decided to assess the biological functions of these groups of genes. We therefore searched for significant enrichments of Gene Ontology terms (GO) in each cluster using GoMiner [27]. In the AMC, only 3 peaks (peaks 1-3) could be associated with significant GO functions (Figure 2B peaks 1, 2 and 3). Complete gene lists for peaks 1-3 are presented in [Additional file 3 and 4].

In peak 3, the 26 genes overexpressed in V1 AMC were significantly associated with the over-represented GO term " signal transducer activity " (GO:0004871, p $=0.0008$, see also Table 3). Significant enrichments of 


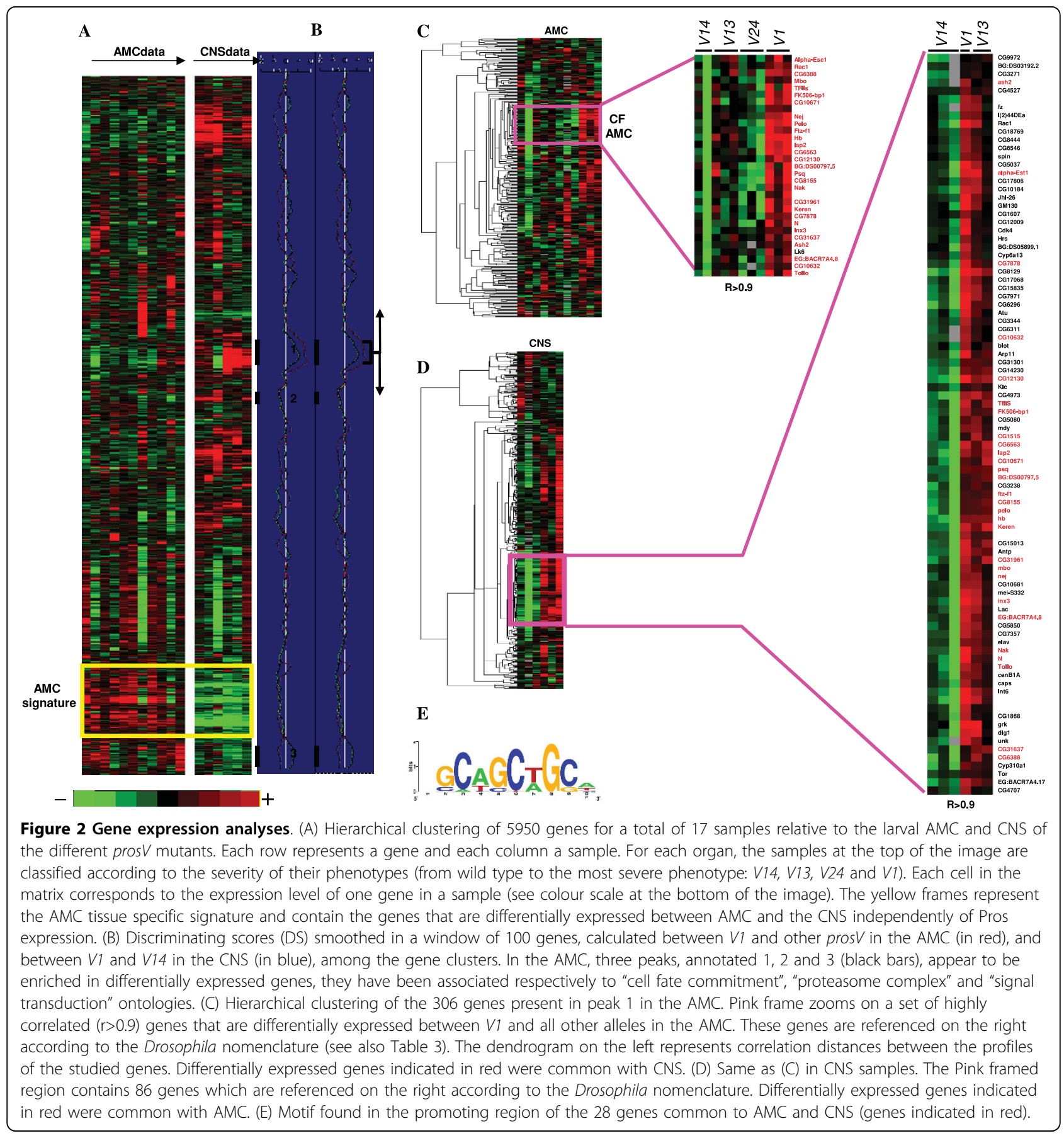

the GO term "proteasome complex" (GO:0000502, p < $10^{-5}$, see also Table 3) were found for 9 genes in peak 2 . All of these genes were underexpressed in V1 AMC. Peak 1, with the highest DS, was common to AMC and $\mathrm{CNS}$ and associated with the over-represented GO term "cell fate commitment" (GO:0045165, p = 0.0003). Inside this peak, a cluster of 29 genes overexpressed in V1 AMC and highly correlated ( $r>0.9$, Figure $2 \mathrm{C}$, Table 3) was isolated and we found a cluster of 86 genes overexpressed in $V 1 \mathrm{CNS}$ and correlated ( $\mathrm{r}>0.9$, Figure 2D, see also [Additional file 5: Supplemental Table S1]) in the same peak. Interestingly, among the $86 \mathrm{CNS}$ genes, 28 (represented in red in the Figure 2D) also belonged to the AMC gene list (see also Table 3 and [Additional file 5: Supplemental Table S1]).

Finally, to assess our microarray analysis, we quantified the expression of seven selected genes by Q-PCR. As shown in Table 4, our results were consistent with 
Table 3 Genes identified as putative Pros targets and their manual annotation

\begin{tabular}{|c|c|c|}
\hline Genes & symbol & $\begin{array}{l}\text { Biological function in larvae (manual } \\
\text { annotation) }\end{array}$ \\
\hline \multicolumn{3}{|c|}{ Cell fate commitment (GO:0045165, $p=0.0003)$} \\
\hline$\alpha E s t 1^{*}$ & CG1031 & Sensory neuron morphogenesis \\
\hline Art3* & CG6563 & Not studied in larvae \\
\hline $\operatorname{Ash} 2^{*}$ & CG6677 & $\begin{array}{l}\text { Neurite outgrowth, synapse formation, growth, } \\
\text { sensory organ development }\end{array}$ \\
\hline CG10632* & CG10632 & Unknown \\
\hline CG10671* & CG10671 & Unknown \\
\hline$\overline{C G 3021^{*}}$ & CG3021 & Unknown \\
\hline$\overline{C G 31637^{*}}$ & CG31637 & Unknown \\
\hline$\overline{C G 31961^{*}}$ & CG31961 & Unknown \\
\hline CG31731* & CG31731 & Unknown \\
\hline CG6388 & CG6388 & Neurite outgrowth \\
\hline CG7878* & CG7878 & Unknown \\
\hline CG8155* & CG8155 & Unknown \\
\hline$\overline{D P A L 1^{*}}$ & CG12130 & Neuropeptide biosynthesis \\
\hline $\begin{array}{l}\text { FK506- } \\
b p 1^{*}\end{array}$ & CG6226 & Autophagy; growth \\
\hline$\overline{F t z-F 1^{*}}$ & CG4059 & Autophagy, sensory organ formation, olfaction \\
\hline$\overline{H b^{*}}$ & CG9786 & $\begin{array}{l}\text { Labial segment formation including sense } \\
\text { organ }\end{array}$ \\
\hline lap2* & CG8293 & Autophagy, sensory organ development \\
\hline $\ln \times 3^{*}$ & CG1448 & Not studied in larvae \\
\hline Keren* & CG32179 & Autophagy, sensory organ development \\
\hline$M b o^{*}$ & CG6819 & Tracheal system development \\
\hline $\mathrm{Nak}^{*}$ & CG10637 & Not studied in larvae \\
\hline$\overline{N e j}{ }^{*}$ & CG15319 & Synaptic transmission, autophagy \\
\hline Notch $^{*}$ & CG3936 & $\begin{array}{l}\text { Neurite outgrowth, nutrient sensing/growth, } \\
\text { sense organ formation, olfaction }\end{array}$ \\
\hline Pelo* & CG3959 & Not studied in larvae \\
\hline Psq* & CG2368 & Sensory organ development, olfaction \\
\hline Rac1* & CG2248 & Neurite outgrowth, sensory organ development \\
\hline$\overline{T o l l o *}$ & CG6890 & $\begin{array}{l}\text { Synaptogenesis, wing development, immune } \\
\text { response }\end{array}$ \\
\hline TFIls* & CG3710 & Not studied in larvae \\
\hline LK6 & CG17342 & Autophagy growth, nutrient sensor mechanism, \\
\hline \multicolumn{3}{|c|}{ Proteasome complex (GO:0000502, $\mathrm{p}<10^{-5}$, ) } \\
\hline Pros 26.4 & CG5289 & Neuronal remodelling, Autophagy \\
\hline Pros $\beta 2$ & CG3329 & $\begin{array}{l}\text { Neuronal remodelling, Synaptic transmission, } \\
\text { autophagy, sensory organ formation }\end{array}$ \\
\hline Pros26 & CG4097 & $\begin{array}{l}\text { Neuronal remodelling, Synaptic transmission, } \\
\text { autophagy }\end{array}$ \\
\hline Pros $\alpha 6$ & CG18495 & $\begin{array}{l}\text { Neuronal remodelling, Synaptic transmission, } \\
\text { autophagy }\end{array}$ \\
\hline $\operatorname{Pros} \alpha 7$ & CG1519 & $\begin{array}{l}\text { Neuronal remodelling, Synaptic transmission, } \\
\text { autophagy }\end{array}$ \\
\hline ProsMA5 & CG10938 & Not studied in larvae \\
\hline RPN1 & CG7762 & Neuronal remodelling, Autophagy \\
\hline RPN2 & CG11888 & Neuronal remodelling, Autophagy \\
\hline RPN5 & CG1100 & Neuronal remodelling, Autophagy \\
\hline
\end{tabular}

the microarray data except for the $h b$ (hunchback) gene found to be overexpressed in the CNS but not in the AMC. Because the two methods have different sensitivities, the magnitude of the change determined by microarray and real time PCR is not the same. The orientation of changes, however, is identical.

An interesting observation was that we found highly correlated genes responding to Pros variation in both CNS and AMC. This tight correlation in two different tissues could suggest that these genes may be controlled by common transcription factors including Pros. We searched for transcription factor binding sites that were common to these 28 genes. We used a Gibbs sampling method [28] on the -1700 to +300 bp promoter region of these genes. This method allowed the determination of degenerated motifs, described by a position weight matrix (PWM), in a set of sequences by iterative sampling.

We found a motif shown as a Logo [29] in Figure 2E. It notably included a CAGCTG core. This motif shows weak and probably not significant similarities with other Pros motifs previously proposed for Drosophila: TAAGNCT [25], CACNNCT [12], TAAGACG [30]. Therefore, additional experiments are now necessary to see whether the motif identified in this study could really bind the Prospero transcription factor in vivo.

Additional manual annotation to specify the role of pros putative target genes in Drosophila larvae

Our microarray analyses showed that peak 1 contained 29 overexpressed genes associated with the GO annotation, "cell fate commitment" (Table 3). These data are not consistent with our previous studies showing that pros is not involved in cell fate determination in the larval AMC [8]. We were intrigued by this discrepancy and therefore we looked more deeply for the function of these genes in the larvae. Interestingly, though most of the genes present in this peak were associated with cell fate determination in embryos, such evidence was mostly missing for the larvae peripheral nervous system (PNS). Thus, it is likely that the GO annotation was mostly deduced from the reported function of these genes in Drosophila embryos. Therefore, to more specifically identify the role of these genes in the Drosophila larva PNS, we used additional manual annotation.

The first step consisted in compiling all of the information available on the role attributed to each of the 64 genes identified from peaks 1-3, but most specifically in Drosophila larvae. The information was collected using Flybase, mutant analysis, associated phenotypes, research articles and microarray data. As much as possible, we selected only data that reported the function of these genes in the larval nervous system and more specifically the sensory system. Out of the 64 genes, we found that 27 had unknown biological functions or had not been 
Table 3: Genes identified as putative Pros targets and their manual annotation (Continued)

\begin{tabular}{|c|c|c|}
\hline & Signal tra & isduction (GO:0004871, $\mathrm{p}=0.0008$ ) \\
\hline$B n l$ & CG4608 & Neurite outgrowth \\
\hline CaMKI & CG1495 & Synaptic transmission \\
\hline CG10011 & CG10011 & Unknown \\
\hline CG10702 & CG10702 & Autophagy \\
\hline CG1088 & CG10882 & Unknown \\
\hline CG31714 & CG31714 & Unknown \\
\hline CG4839 & CG4839 & Unknown \\
\hline CG5790 & CG5790 & Unknown \\
\hline CG7536 & CG7536 & Unknown \\
\hline CG7800 & CG7800 & Unknown \\
\hline CKII $\alpha$ & CG17520 & Sensory organ development \\
\hline Dok & CG2079 & Sensory organ development \\
\hline$\overline{E G F R}$ & CG10079 & $\begin{array}{l}\text { Neurite outgrowth, synapse formation, growth, } \\
\text { autophagy sensory organ development, } \\
\text { olfaction }\end{array}$ \\
\hline feo & CG11207 & Mitotic spindle organisation \\
\hline Gek & CG4012 & Actin polymerisation \\
\hline GWl & CG7719 & $\begin{array}{l}\text { Neurite outgrowth, synaptic transmission, } \\
\text { mitotic cell cycle }\end{array}$ \\
\hline $\operatorname{lnaC}$ & CG6518 & Not studied in larvae \\
\hline Kdelr & CG5183 & Not studied in larvae \\
\hline LimK1 & CG1848 & Neurite outgrowth, synaptic transmission \\
\hline Lok & CG10895 & Cell cycle, DNA damage checkpoint \\
\hline LOCO & CG5248 & Not studied in larvae \\
\hline Mcr & CG7586 & Olfaction \\
\hline$P h K \gamma$ & CG1830 & Not studied in larvae \\
\hline$\overline{P v r}$ & CG8222 & $\begin{array}{l}\text { Hemocyte formation, dorsal closure, } \\
\text { macrochaete formation }\end{array}$ \\
\hline Rh7 & CG5638 & Not studied in larvae \\
\hline Toll-6 & CG7250 & Not studied in larvae \\
\hline
\end{tabular}

The 64 genes found highly correlated in the peak 1,2 and 3 are grouped according to their respective $\mathrm{GO}$ annotation class. The most significant classes of genes enriched in our list are "Cell fate commitment", "proteasome complex" and "signal transduction". The p value indicates the probability for a given ontology to be associated at random to this cluster. The first 28 genes indicated in bold and by an asterisk share a common DNA motif (CAGCTG) in their promoter and were also found to be differentially expressed between $V 1$ and V14 CNS.

The last column on the right specifies the known biological function (manual annotation) of these genes in the Drosophila larvae (Full references can be found in the main text and in [Additional file 5: Supplemental Tables S2-S4]). This manual annotation allowed the attribution of biological function to 37 genes. Some genes have either never been studied in larvae or their respective functions are currently unknown. By contrast to the $\mathrm{GO}$ annotation (mostly deduced from embryos), the use of manual annotation indicates that the dysfunction of pros leads in larvae to the misregulation of genes that mostly deal with neurite outgrowth, growth and autophagy and sensory organ formation (mainly olfactory). All genes were found to be overexpressed in the mutant $V 1$ AMC except for the 9 genes associated with the Proteasome complex $\mathrm{GO}$ annotation. documented in larvae (Table 3). Since the genes encoding the subunit of the proteasome complex are underexpressed and the remaining genes are overexpressed in the $V 1 \mathrm{AMC}$, a description of the phenotype generated by the upregulation and downregulation of the corresponding genes in larvae was given [Additional file 5: Supplemental Tables S2-S4]. Though many phenotypes were available for a gene, we selected only those reported for the nervous system and preferentially for the PNS.

Analysis of the resulting compiled data on larva [Additional file 5: Supplemental Tables S2-S4] revealed that the 37 genes fell into at least one of the following functional categories: (1) neurite outgrowth and/or synaptic transmission; (2) growth, autophagy; (3) sensory organ (mainly olfactory) development. A list of these genes and their associated annotation terms is summarized in Table 3, and a schematic representation is given in Figure 3. As shown in Figure 3, some genes can be associated with two functional classes, and four genes (EGFR, Notch, Ash 2 and $\operatorname{pros} \beta$ ) are associated with the three functional categories: neurite outgrowth, autophagy, and olfactory system development.

\section{Genes involved in neural processes and synaptic transmission are misregulated in the V1 AMC mutant}

One of the functional categories deduced from manual annotation associates some putative Pros target genes with neurite outgrowth and/or synaptic transmission (Figure 3). Although synaptic transmission and neurite outgrowth belong to different functional categories, we decided to keep these genes in the same class since many of them are involved in both synaptic transmission and neurite outgrowth.

Mostly, the genes are overexpressed in the larval $V 1$ AMC, (Table 3). It has been reported that the upregulation of most of these candidates inhibits neurite outgrowth in larval neurons (reported phenotypes are shown in [Additional file 5: Supplemental Table S2]). This is clearly the case for EGFR (Epidermal Growth Factor Receptor), $N$ (Notch), bnl (branchless) and Rac1 [31-33] whose overexpression was previously shown to inhibit axon extension in larval neurons. This is also the case for $g w l$ (greatwall), limK1 (lim-kinase 1), $\mathrm{Nej}$ (Nejire) or CG6388, Pvr, whose upregulation induces axon pathfinding defects or impaired neurotransmitter release in the larval neuromuscular junction (NJM) [34-38]. Interestingly, similar axon pathfinding and NMJ defects were observed in the $V 1$ mutant [8].

We have noticed that most of the genes included in this functional class can also drive neural connectivity remodelling in larvae, a process particularly important during metamorphosis. EGFR, Notch, bnl, Rac1 [31-33], and the genes associated with the ubiquitin-proteasome system were all reported to be involved in axon 
Table 4 Validation of microarray data using real time PCR.

\begin{tabular}{|c|c|c|c|c|c|}
\hline \multirow[b]{3}{*}{ Gene Primers } & \multicolumn{5}{|c|}{ Relative expression level $V 1 / V 14$} \\
\hline & & \multicolumn{2}{|c|}{ AMC } & \multicolumn{2}{|c|}{ CNS } \\
\hline & & Microarray & Q-PCR & Microarray & Q-PCR \\
\hline caps & $\begin{array}{l}\text { F 5'GCAGCCTGGATGAAGGTTAA 3' } \\
\text { R 5'ATGGCGCAGCCATAGTAGTC 3' }\end{array}$ & 1.38 & 0.63 & 3.8 & 2.38 \\
\hline$C d k 4$ & $\begin{array}{l}\text { F 5' TACAACAGCACCGTGGACAT 3' } \\
\text { R 5' GGTCCAGCTGATTCTITTCG 3' }\end{array}$ & 0.95 & 1.3 & 4.99 & 2.5 \\
\hline$h b$ & $\begin{array}{l}\text { F 5' CCTTCCAGTGCGACAAATG 3' } \\
\text { R 5' ATCCGCACAACGGTACTGA 3' }\end{array}$ & 6.71 & 0.85 & 6.38 & 1.6 \\
\hline lap2 & $\begin{array}{l}\text { F 5'AAGGACTGGCCGAATCCCAACATC 3' } \\
\text { R 5' CGTTGCACCAAACACACTTC 3' }\end{array}$ & 3.69 & 2.16 & 6.48 & 1.9 \\
\hline nak & $\begin{array}{l}\text { F 5'AGGAAGCATCACAGCAAAAT 3' } \\
\text { R 5'GCACCAGGAGCAGCTGTAAC 3' }\end{array}$ & 1.75 & 1.36 & 0.97 & 1.95 \\
\hline nej & $\begin{array}{l}\text { F 5'AATGGATCCAACGGATATCTCT } 3^{\prime} \\
\text { R 5'CTGATCCGACCAGCCACTAT 3' }\end{array}$ & 3.26 & 1.63 & 3.79 & 3.75 \\
\hline Notch & $\begin{array}{l}\text { F 5'AACACCGTTCGCGGAACTGATACCG 3' } \\
\text { R 5'GGTITGCCATTGAGTGTG 33' }\end{array}$ & 2.9 & 1.76 & 8.96 & 2.52 \\
\hline
\end{tabular}

The relative expression level (V1/V14) of selected genes was measured using the Q- PCR or microarray analysis data; Our results were consistent with the microarray data except for the $h b$ (hunchback) gene found to be overexpressed in the CNS but not in the AMC. The values in gray correspond to the genes found differentially expressed between $V 1$ and V14 in the CNS but not in the AMC using microarray analysis. Accordingly, no significant variation was found for these genes in the AMC, using Q-PCR.

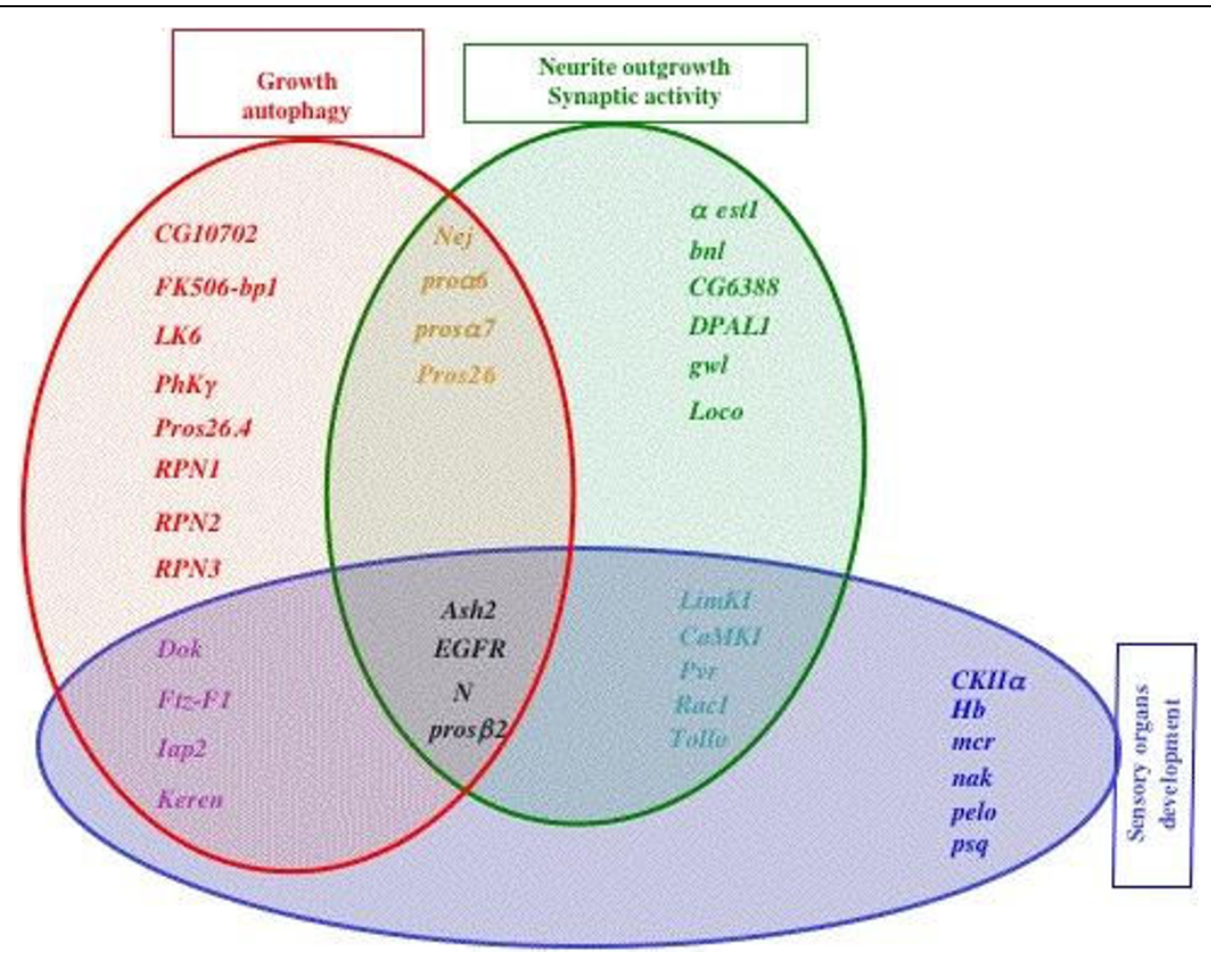

Figure 3 Schematic representation of the overlapping function attributed to the AMC putative Pros target genes. The functional categories were established using a manual annotation (the criteria used for this annotation are indicated in the text, see also for further phenotypic description and corresponding references [Additional file 5: Supplemental Tables S2-S4]). The three functional groups identified are represented by three distinct colored sets. The genes located at the intersection between two sets can assume both functions. It should be noted that the genes indicated in black (EGFR, Notch, Ash2 and pros $\beta 2$ ) belong to the three functional groups: neurite outgrowth, sensory organ development, and growth/autophagy. 
extension/retraction, pruning and morphogenesis of larval peripheral sensory neurons [Additional file 5: Supplemental Table S2]. Indeed, though most larval sensory neurons will degenerate during metamorphosis, some persist as neurons and undergo stereotyped pruning of their dendrites and axon terminal branches during early metamorphosis [39].

We were not surprised to find that the genes encoding the different proteasome subunits (Pros $\alpha 7, \operatorname{Pros} \beta 2$, Pros $\alpha 6$, Pros $\alpha 26$ ) are downregulated in V1 AMC (Figure 3 , Table 3$)$. Indeed, the acute regulation of their protein level is a primary determinant of protein turnover and neurotransmission strength [40,41].

Recently, an elegant study of Choksi et al. [25] showed that pros is required for activation of neuronal differentiation genes in embryos and identified $N, b n l, L i m K I$, EGFR and PVR, pros $\alpha 6$ as putative pros targets in embryos. This reinforces our finding suggesting that in the larval AMC, pros plays a crucial role in the modulation of neuronal activity through the control of genes involved in neurotransmission and synaptic plasticity.

Loss of pros function alters the expression of genes involved in autophagy and growth

The second functional group that emerges from our analysis includes candidates that play a critical role in the control of autophagy, a process used to provide energy and nutrients during metamorphosis and early adulthood.

The association between Pros and the regulation of autophagy is mainly attested by the upregulation of genes such as CG10702, EGFR, Keren (EGFR ligand), Ftz-F1 (Ftz transcription factor 1), FK506-bp1 (FK506binding protein 1), Iap2 (Inhibitor of apoptosis 2), nej, Notch and genes associated with proteasome complex (Table 3, Figure 3, see also [Additional file 5: Supplemental Table S3]).

Some of the genes cited above were also found to mediate cell growth (Table 3 and [Additional file 5: Supplemental Table S3]). However, it is not yet clear if the overexpression of these genes systematically inhibits cell growth. For example, the upregulation of LK6 (protein serine/threonine kinase) or FK506-bp1 leads to either the activation or inhibition of cell growth in a contextdependent way [42-44].

We have already mentioned that Notch and EGFR pathways were involved in neurite outgrowth (see above), interestingly, we found that these two pathways were also associated with both the regulation of autophagy and cell growth control [45,46] (Figure 3), suggesting that Pros could mediate all of these functions through the modulation of these two pathways.

Our finding that pros is associated with the expression of genes involved in growth and or autophagy is consistent with the phenotypic defects observed in $V 1$ homozygote mutants: i) individuals died before reaching puparium formation; ii) surviving larvae and pupae remained much smaller than wild-type individuals; iii) numerous labelled cells were observed in the fat body using PGal4 enhancer trap line V1 [9].

It is interesting to note that many of the genes found in this functional group are directly or indirectly associated with insulin-signalling pathways and more specifically the insulin/TOR (target of rapamycin) pathway, an important mediator of growth, autophagy and nutrient sensing [Additional file 5: Supplemental Table S3].

\section{Pros and the olfactory system}

Pros was detected both in the terminal (TO: mainly gustatory) and in the dorsal (DO: mainly olfactory) organs of the larval AMC [8]. Accordingly, we found that pros loss of function in the AMC induced the upregulation of all candidate genes (except pros $\beta 2$ ) that were known to be involved in the development of sensory organs (Figure 3, Table 3). Most of our knowledge on the function of these genes came from studies done on adult Drosophila sensory organs [Additional file 5: Supplemental Table S4]. For example, it has been reported that mutations in the genes ash2 or ckII alpha (Casein kinase II alpha subunit) can elicit supernumerary or ectopic adult sensory organs $[47,48]$. Similarly, overexpression of Iap 2 or limK1 induces respectively additional macrochaetes [49] or ectopic glomeruli in adult antennae lobes [36]. The transmembrane receptor Notch and the epidermal growth factor receptor EGFR also seem to play an important role in the organisation, remodelling and function of the olfactory system [Additional file 5: Supplemental Table S4]. This confirms previous observations which showed that they were respectively required for selecting the sensory organ precursor lineages $[50,51]$ and for the development of some of the neurons and cuticular structures of the antenno-maxillary sensory complex [52].

\section{Discussion}

Pros may regulate genes essential for neurite outgrowth and remodelling

In the AMC, the transcription factor Prospero is expressed in a cluster of cells (composed of neuronal and support cells, but not glial cells) that emerge during embryonic life and are maintained till the end of the larval stages. In embryos, Pros was reported to be involved in cell fate decision and in cell-cycle control. By contrast, our earlier data from the larval AMC rather suggested that pros could assume more restricted functions, such as the control of neuron-specific functions [8]. The present study confirms this hypothesis and shows that in the chemosensory organs dedicated to larval olfactory and gustatory sensing, prospero could regulate genes involved in neurite outgrowth and synaptic transmission. 
Since pros was clearly shown to control axonal and dendritic outgrowth [53], we cannot exclude the possibility that the connection of pros with several genes that drive synaptic activity could be the indirect consequence of its involvement in neurite outgrowth control. In this respect, it is interesting to mention that a recent study [54] showed that axon targeting of the R7 Drosophila photoreceptor cells to their synaptic partner requires R7-specific transcription factor Prospero. These authors proposed that Pros could promote cell-type-specific expression of sensory receptors and cell-surface proteins regulating synaptic target specificity.

As previously mentioned, some of the genes identified in this functional class are also involved in neural connectivity remodelling. How can this be achieved if the AMC is completely histolysed? In fact, in Drosophila, not all sensory neurons degenerate; Some larval neurons persist and remodel to take on a new role in the adult system $[55,56]$. During the metamorphosis larval arbors of these neurons are pruned back and new adult-specific arbors are generated through a subsequent period of outgrowth. It seems that the neurites of these persistent larval neurons are used to partly guide axons of adult sensory neurons towards and within the CNS [55]. Therefore, histolysis and remodelling are two processes that are achieved during metamorphosis and could concern distinct neurons.

Does Pros play any role in AMC neuronal remodelling? We cannot actually answer the question. However, it has been previously reported that the insulin and epidermal growth factor signalling pathways, as well as ubiquitin-specific proteases are all required for the regulation of Drosophila neuronal remodelling [57]. Interestingly, all of these components emerge clearly from our analysis.

Actually, no work was done on the Drosophila larvae anterior sense organ in order to check whether some of the sensory neurons (which have also an embryonic origin) persist and remodel to take place in the adult olfactory or gustatory system. Therefore, the question is left open. At least the answers will provide important insights into the mechanisms that govern developmental plasticity in insect nervous systems.

In summary, our data collected from larval AMC and the previous genome wide expression profiling done on embryos [25] confirms that pros is associated with the regulation of neuronal specific genes. In this respect, it is essential to note that except for a few genes (126), most of the Pros target genes identified ( 1000) in Choksi et al. [25] were not represented on our microarrays. For this reason, and because our experiments were performed on isolated individual larval tissues, it is not possible to determine whether the genes identified by these authors are specifically expressed in embryos and/ or in tissues other than AMC.

\section{Prospero and the insulin pathway}

In Drosophila, the insulin/TOR signalling pathway [58] is divided into two branches. The insulin and its downstream effectors P13 and FOXO (forkhead box) represent one branch [59] of this pathway, while the other branch acts through the TOR family of Serine-Threonin kinases $[60,61]$. It has been shown that the insulin/TOR signalling pathway inhibits autophagy (For review see [58]) and controls growth by regulating ribosome biogenesis and protein biosynthetic capacity $[62,63]$. Columbani et al. [63] demonstrated that the TOR pathway is a nutritional checkpoint that participates in the systemic control of larval growth emanating from the Fat body.

Our microarray analysis has revealed a group of highly correlated pros candidate genes (correlation index: 0.9) that are either controlled by the insulin/TOR signalling pathway or are directly involved in the signalling cascade. This is the case for Ash2 [64] which was found to be regulated by TOR signalling. Similarly, FK506-bp1 affects autophagy through the modulation of FOXO [44] and $L k 6$ was reported to be a direct FOXO Target [62]. Therefore it seems that in the larval AMC, Pros could be associated with growth, autophagy and nutrient sensing through the regulation of genes that are directly or indirectly linked to the insulin/TOR pathway. Interestingly, TOR was found to be differentially expressed in the $V 1$ pros mutant in the CNS [Additional file 5: Supplemental Table S1].

\section{Conclusion}

As previously described, loss of pros function in the AMC induced several alterations including axon pathfinding defects and abnormal growth and taste responses. This is consistent with our microarray results showing that in the larval AMC, Pros expression is associated with the regulation of genes involved in the control of neurite outgrowth, mediation of growth and autophagy and in the organisation and function of the olfactory system. The mechanism by which all of these functions are achieved by pros in the AMC is presently not known but EGFR and/or Notch pathways could play a central role. Several lines of evidence are in favour of this hypothesis.

1- Four ligands are known to bind EGFR receptor: Keren, Gurken, Spitz, and Vein [65]. Two of these were identified as potential targets of Prospero: Keren in both larval AMC and CNS and Gurken (Grk) in the larval CNS only (see Table 3 and [Additional file 5: Supplemental Table S1]). Moreover, Notch and EGFR were identified as putative Pros target genes in both embryos 
[25] and larval AMC, indicating that they could play a central role.

2- It has been reported that EGFR signalling is required for the development of some of the neurons and cuticular structures present in the AMC $[66,67]$. In this respect, it is interesting to point out that EGFR involvement has been reported during the development of mouse gustatory epithelia in the palate and tongue [68].

3- The expression of Notch, EGFR and Pros have been shown to be tightly linked. It has been demonstrated that normal levels of Pros expression in photoreceptor R7 cells in the Drosophila eye require EGFR signalling as well as Notch activation [69,70]. In addition, a recent analysis has shown that in R7 cells, Notch and EGFR cooperate in a complex way to promote pros transcription [71].

Although these data suggest that Notch and EGFR could play a central role in the mechanism by which Prospero carries out its function in the larval AMC, this hypothesis has still to be validated. In the future, it will be of great interest to explore in detail the mechanism by which all of these functions are accomplished by the homeodomain transcription factor Prospero.

\section{Methods}

\section{Drosophila strains}

All strains were maintained on standard cornmeal and yeast medium at $25^{\circ} \mathrm{C}$. The pros $V$ strains used in this study have already been described [72]. Briefly, prosV13 (V13) and prosV24 (V24) derived from the same prosV1 (V1) allele which contains the full length PGal4 transposon inserted upstream $(-216 \mathrm{bp})$ of the pros coding region. The resulting behavioural and developmental anomalies observed in these mutants have been previously reported [8], and are summarised in Table 1. Additional descriptions of the expression pattern of these different alleles in the larval CNS are also provided in the [Additional file 2].

\section{Isolation of AMC and CNS tissue}

Around 150 larvae were used to obtain the AMC and CNS samples. The anterior region of the Larva was dissected to isolate CNS and AMC. The AMC region is not a well-defined tissue but is rather constituted by a small group of cells located in front of the hooks. Therefore, to maintain AMC integrity we kept the cuticle around it as well as the hooks.

\section{Immunohistochemistry experiments}

Staining experiments were performed as previously described by Guenin et al. [8] Briefly, isolated larval AMC from embryos at stage 10-17 were incubated with various primary antibodies: MR1A mouse anti-Prospero at 1:4 dilution, rat anti-Elav at 1/1000 (a neuronal marker; provided by A. Giangrande), and rabbit anti- phosphohistone $\mathrm{H} 3$ at 1/1000 (a marker for mitotic activity; SIGMA). The following secondary antibodies were used to visualize these primary antibodies: antimouse Cy3 at 1/100 (Sigma); anti-mouse Alexa 594 anti-rat Alexa 488 at 1/400 (Molecular probes, USA); anti-rabbit Alexa 488 at 1/400 (Molecular probes, USA). AMC and CNS were mounted on Vectashield (Vector Laboratories, CA) before inspection under a fluorescence microscope (Leica DMRB) or a confocal microscope (Leica 4SD).

\section{RNA extraction and CDNA labelling}

Total RNA from third instar larvae was extracted from isolated AMC and CNS, according to Guenin et al. [8]. Four independent extractions were performed for each sample condition. RNA integrity was checked on denaturing formaldehyde agarose gels. The presence of clear bands corresponding to the 28s and 18s RNA with a 2:1 ratio and the absence of a smear were used to assess the RNA quality. Total RNA $(3.0 \mu \mathrm{g})$ were treated with RQ1 RNase-free DNase (Promega) and reverse transcripted in presence of ${ }^{33}[\mathrm{P}]$ dATP (Amersham Pharmacia Biotech, Bucks, United Kingdom), Random Primers and the reverse transcriptase (Maloney Murine Leukaemia Virus, Invitrogen).

\section{Microarray experiments}

Nylon membrane microarrays provided by the TAGC platform (Marseille-Nice Genopole) were used. They contained 7500 amplification PCR products of unique full length cDNA clones from the Drosophila Gene collection release version 1.0 (Berkeley Drosophila Genome project). To verify the quality of spotting on the microarrays and the amount of DNA accessible for each spot, a vector probe (labelled oligonucleotide common to all spotted PCR products) hybridization was performed. Hybridization of ${ }^{33}[\mathrm{P}]$ labelled probes was conducted for $24 \mathrm{~h}$ at $68^{\circ} \mathrm{C}$ in $500 \mu \mathrm{l}$ of hybridization buffer $(5 \times$ SSC, $5 \times$ Denhardt's, $0,5 \%$ SDS). After 3 washing of $1 \mathrm{~h}$ in 500 $\mathrm{ml}$ of washing buffer $(0,1 \times \mathrm{SSC}, 0,2 \% \mathrm{SDS})$ at $68^{\circ} \mathrm{C}$, arrays were exposed overnight to phosphor imaging plates which were scanned using a BAS 5000 (Fuji, Raytest, Paris France).

\section{Data processing and analysis}

Signal intensities were quantified using ArrayGauge software (V1.3; Fuji, Paris, France). All images were carefully inspected to exclude spots with overestimated intensities due to neighbourhood effects. Artefacts were eliminated by visual inspection. Spots were excluded from the quantification, if they were contaminated by overflowing neighbouring spots or if artefacts are present on the membrane. Overflowing spots were also eliminated. One sample was discarded (CNS V14) because of bad vector signals. The variability due to experimental conditions was eliminated by using a local weighted scattered plot smoother analysis (LOWESS, [73]). The data were then 
filtered and only values found to be twice the mean local background value were kept. Correlation coefficients between expression measurements of two identical alleles ranged from 0.74 to 0.93 for the same tissue. Data were then log transformed.

Genes belonging to the same biological function or cell type are known to exhibit correlated expression [74]. Thus we searched for sets of genes with correlated expression that were differentially expressed between mutants. We used a method to detect groups of correlated genes and a statistical method to detect differential expression among these groups. Different methods were able to detect correlated expressions. We chose hierarchical clustering which has the advantage of not fixing a priori the number of classes or the number of genes per class. The statistical method used to detect genes differentially expressed between the wild type and pros mutants was the Discriminating Score [75], which is very similar to the widely used SAM method [76]. As the expected number of genes was not known, we calculated an average DS in a sliding window on the cluster. This allowed us to detect peaks of the optimal size. These peaks corresponded to genes with correlated expression and differentially expressed between mutants. For the clustering, we used the Cluster program with Pearson correlation distance and average linkage as the aggregation strategy. The results were displayed using TreeView [26]. The DS measures the difference in gene expression between 2 groups of samples. If M1 represents mean expression of a given gene in wild type samples, and M2 the mean expression of the same gene in pros mutant samples, and SD the standard deviation of this gene in all considered samples, DS $=(\mathrm{M} 1-\mathrm{M} 2) /$ (SD). As V13, V14 and V24 have a normal Pros expression pattern in the AMC, they were considered wild type. The DS between $V 1$ and all of the other alleles for the AMC was calculated for each gene. As V13 and V24 exhibited a distinct pattern in the CNS, for each gene, we calculated a DS between the V1 and V14 allele for the CNS. The score for each gene was then smoothed by calculating the mean score in a sliding window of 100 genes.

Finally, to highlight very tightly correlated genes in the main peak (peak 1) for each tissue, we performed a second hierarchical clustering with the genes of this peak, separately in the CNS and AMC.

The complete dataset is available through the National Center for Biotechnology Information (NCBI), in the Gene Expression Omnibus database http://www.ncbi. nlm.nih.gov/geo/ under the GSE12178 accession number.

\section{Functional Annotation}

Functional annotations of gene clusters were performed using GoMiner software [27] and the Gene Ontology database [77]. GoMiner determines significant enrichments of GO terms in a cluster of genes. This is performed by comparing the frequencies of each GO term in the cluster and in the microarray using Fisher's exact test.

\section{Research of a putative common motif in the promoter of} co-expressed genes

Promoting regions of co-expressed genes were collected from the Ensembl ftp site http://www.ensembl.org/ index.html The sequence located from -1700 to $+300 \mathrm{bp}$ according to the +1 transcription start site of each gene was extracted. Interspersed and simple repeats were masked. These sequences were searched for a common motif using the Gibbs sampling method [28] available at the RSA Tools website: http://rsat.ulb.ac.be/rsat/. This method allowed to determine degenerated motifs described by a position weight matrix (PWM, a probabilistic model of residue frequencies at each position), in a set of sequences by iterative sampling. The initialisation step of the algorithm selects a random subsequence in each sequence to be searched. The predictive step builds a PWM from all the subsequences except one. The sampling step selects a new subsequence from the excluded sequence using a weighting strategy based on the PWM scores. The predictive and the sampling steps are iterated a given number of times or until convergence. We performed many Gibbs sampling runs as this method is stochastic. The motif found was identified in most of the runs. We used a Logo representation [29] to show the information content of the PWM.

\section{Q-PCR validation}

In order to validate the Microarray results, seven genes were selected and their expression levels were quantified by Q-PCR for both prosV1 and prosV14. For each RNA extraction used for microarrays, a sample was collected in order to perform Q-PCR experiments. Reverse transcriptions were done from $2 \mu \mathrm{g}$ of total RNA as described in Guenin et al. [8]. The selected genes and the corresponding primers, designed using Primer Express $^{\mathrm{Tm}}$ (Applied Biosystems) parameters, are indicated in Table 4. Q-PCR reactions were performed with 1:10 diluted cDNA in $2 \times$ SybrGreen PCR master mix (Applied Biosystems) with each specific primer (See table 4) or control primers (actin 5C F 5'GCCCATCTACGAGGGTTATGC3' and actin $5 \mathrm{C} \mathrm{R}$ 5'CAAATCGCGACCAGCCAG3'). Signals were measured with $A B I$ Prism $7000^{\text {ma }}$ Sequence Detection System software (Applied Biosystems). All signal thresholds to be compared were standardized with the actin $5 \mathrm{C}$ mRNA [8].

Additional file 1: Mitotic Activity in the AMC region, in stage 11 and stage 16 embryos. Wild type embryos from stage 11 to 16 were stained with Pros (red) and H3p (green) which label cells in division. (A) 
Mitotic activity is observed until stage 11-12 (arrow) while no more activity is detected from stage 16 embryos (B) in the AMC. Scale bar correspond to $20 \mu \mathrm{m}$.

Click here for file

[http://www.biomedcentral.com/content/supplementary/1471-2164-1147-S1.GIF ]

Additional file 2: Expression pattern of V24 in the third instar larval CNS. The Pros (A) and Elav (B) expression pattern as well as the mitotic activity (C) of V24 are shown as compared to the previously reported pattern of V14, V13 and V1 alleles [8]. Although V24 and V13 present the same expression pattern in the AMC, the situation is different in the CNS. As it can be seen Pros (A) and Elav labeling (B) are distinctive for both alleles in the region delimiting the two hemispheres and the Optic lobes (OLs). As compared to V13, V24 presents a decrease of the staining in this region for these two markers (B). In ventral nerve cord (VNC), V13 shows an important hyperplasia (arrowheads) due to an excess of neurons. In V24, the VNC extremity presents a bifida aspect (arrow). The mitotic activity, revealed by anti-pHistone-H3 $(\mathrm{H} 3 \mathrm{p})(\mathrm{C})$ is strongly increased in V24, especially in the OLs.

Click here for file

[http://www.biomedcentral.com/content/supplementary/1471-2164-1147-S2.GIF ]

Additional file 3: List of the AMC genes represented in the 3 peaks obtained after the application of the discriminating score between V1 and all other alleles for the AMC samples. Peak 1: Differentially expressed genes involved in cell fate commitment. Peak 2: Differentially expressed genes involved in the proteasome complex. Peak $\mathbf{3}$

Differentially expressed genes involved in signal transducer activity. Click here for file

[ http://www.biomedcentral.com/content/supplementary/1471-2164-1147-S3.XLS]

Additional file 4: List of the CNS genes represented in the peak obtained after the application of the discriminating score between $V 1$ and $V 1 \mathbf{4}$ for the CNS samples. The peak contains differentially expressed genes involved in cell fate commitment.

Click here for file

[http://www.biomedcentral.com/content/supplementary/1471-2164-1147-S4.XLS ]

Additional file 5: Supplemental Table S1: Genes found to be differentially expressed between $\boldsymbol{V} 1$ and $V 14$ CNS. We found 86 genes that are highly correlated (coeff> 0,9). Among the 86 genes, 28 were also found to be overexpressed in the V1 AMC (column on the left, gene names are indicated in bold) and contain the common putative pros DNA motif in their promoter. The 58 genes present in the two columns on the right are specifically overexpressed in V1 CNS as compared to V14 CNS. Supplemental Table S2: Phenotypic data related to the candidate genes involved in neurite outgrowth and/ or synaptic transmission. The criteria used for the description of the phenotypes were as follows: (1) if many larval phenotypes were available for a gene, we selected only those observed in the nervous system and preferentially in the peripheral nervous system (PNS). (2) If no larval phenotype was available for a gene, we selected those observed in the embryonic and/or adult PNS. (3) If available, the effect of the upregulation or downregulation of these genes is mentioned respectively for those that are overexpressed or underexpressed in $V 1$ AMC. (4) All studies mentioned were done in Drosophila melanogaster. Supplemental Table S3: Phenotype data related to the candidate genes involved in growth and autophagy. The criteria used for the description of the phenotypes were the same as those for Table S2. Supplemental Table S4: Phenotype data related to the candidate genes involved in sensory organ development and most particularly in olfaction (in bold). The criteria used for the description of the phenotypes were the same as those for Table S2.

Click here for file

[http://www.biomedcentral.com/content/supplementary/1471-2164-1147-S5.PDF]

\section{Acknowledgements}

We thank Nicolas Boulanger and Béatrice Loriod from the TAGC platform for the excellent technical assistance. This work was funded by the Burgundy Regional Council and the Centre National de la Recherche Scientifique.

\section{Author details}

'Institut Pasteur, Pathogénomique Mycobactérienne Intégrée, 25, Rue du Dr. Roux, 75724 Paris Cedex 15, France. ${ }^{2}$ Université de Bourgogne, Facultés des Sciences, Unité Mixte de Recherche 5548 Associée au Centre National de la Recherche Scientifique, 6, Bd Gabriel, 21000 Dijon, France. ${ }^{3}$ INSERM, U915, Nantes, F-44000, France. ${ }^{4}$ Université de Nantes, I'Institut du Thorax, Nantes, F44000, France.

\section{Authors' contributions}

$L G$ and FB generated the microarray data and drafted the manuscript. LG carry out immunohistochemistry and Q-PCR experiments. $L G, M R$ and $R H$, performed the biostatistic analysis. MR performed the motif discovery. FB generated the Drosophila larvae data compilation for manual annotation. FB and $\mathrm{RH}$ provided direction and oversight of the experiments. FB holds the grant. All authors read, corrected and approved the final manuscript.

\section{Received: 17 March 2009}

Accepted: 19 January 2010 Published: 19 January 2010

\section{References}

1. Frederick RD, Denell RE: Embryological origin of the antenno-maxillary complex of the larva of Drosophila melanogaster Meigen (Diptera: Drosophilidae). Int J Insect Morphol Embryol 1982, 11:227-233.

2. Singh RN, Singh K: Fine structure of the sensory organs of Drosophila melanogaster Meigen larva (Diptera: Drosophilidae). Int J Insect Morphol Embryol 1984, 13:255-273.

3. Gerber B, Stocker RF: he Drosophila larva as a model for studying chemosensation and chemosensory learning: a review. Chem Senses 2007, 32(1):65-89.

4. Chu-Wang IW, Axtell RC: Fine structure of the terminal organ of the house fly larva, Musca domestica L. Z Zellforsch Mikrosk Anat 1972, 127:287-305.

5. Chu-Wang IW, Axtell RC: Fine structure of the ventral organ of the house fly larva, Musca domestica L. Z Zellforsch Mikrosk Anat 1972, 130:489-495.

6. Stocker RF: The organization of the chemosensory system in Drosophila melanogaster: a review. Cell Tissue Res 1994, 275(1):3-26.

7. Heimbeck G, Bugnon V, Gendre N, Haberlin C, Stocker RF: Smell and taste perception in Drosophila melanogaster larva: toxin expression studies in chemosensory neurons. J Neurosci 1999, 19(15):6599-6609.

8. Guenin L, Grosjean Y, Fraichard S, Acebes A, Baba-Aissa F, Ferveur JF: Spatio-temporal expression of Prospero is finely tuned to allow the correct development and function of the nervous system in Drosophila melanogaster. Dev Biol 2007, 304(1):62-74.

9. Balakireva M, Gendre N, Stocker RF, Ferveur JF: The genetic variant Voila causes gustatory defects during Drosophila development. J Neurosci 2000, 20(9):3425-3433.

10. Grosjean Y, Lacaille F, Acebes A, Clemencet J, Ferveur JF: Taste, movement, and death: varying effects of new prospero mutants during Drosophila development. J Neurobiol 2003, 55(1):1-13.

11. Chu-Lagraff Q, Wright DM, McNeil LK, Doe CQ: The prospero gene encodes a divergent homeodomain protein that controls neuronal identity in Drosophila. Development 1991, , Suppl 2: 79-85.

12. Hassan B, Li L, Bremer KA, Chang W, Pinsonneault J, Vaessin H: Prospero is a panneural transcription factor that modulates homeodomain protein activity. Proc Natl Acad Sci USA 1997, 94(20):10991-10996.

13. Matsuzaki F, Koizumi K, Hama C, Yoshioka T, Nabeshima Y: Cloning of the Drosophila prospero gene and its expression in ganglion mother cells. Biochem Biophys Res Commun 1992, 182(3):1326-1332.

14. Doe CQ, Chu-LaGraff Q, Wright DM, Scott MP: The prospero gene specifies cell fates in the Drosophila central nervous system. Cell 1991, 65(3):451-464.

15. Vaessin $H$, Grell E, Wolff E, Bier E, Jan LY, Jan YN: prospero is expressed in neuronal precursors and encodes a nuclear protein that is involved in the control of axonal outgrowth in Drosophila. cell 1991, 67(5):941-953. 
16. Hirata J, Nakagoshi H, Nabeshima Y, Matsuzaki F: Asymmetric segregation of the homeodomain protein Prospero during Drosophila development. Nature 1995, 377:627-630.

17. Knoblich JA, Jan LY, Jan YN: Asymmetric segregation of Numb and Prospero during cell division. Nature 1995, 377:324-327.

18. Spana EP, Doe CQ: The prospero transcription factor is asymmetrically localized to the cell cortex during neuroblast mitosis in Drosophila. Development 1995, 121(10):3187-3195.

19. Manning L, Doe CQ: Prospero distinguishes sibling cell fate without asymmetric localization in the Drosophila adult external sense organ lineage. Development 1999, 126(10):2063-2071.

20. Akiyama-Oda Y, Hotta Y, Tsukita S, Oda H: Distinct mechanisms triggering glial differentiation in Drosophila thoracic and abdominal neuroblasts 64. Dev Biol 2000, 222(2):429-439.

21. Freeman MR, Doe CQ: Asymmetric Prospero localization is required to generate mixed neuronal/glial lineages in the Drosophila CNS. Development 2001, 128(20):4103-4112.

22. Li L, Vaessin H: Pan-neural Prospero terminates cell proliferation during Drosophila neurogenesis. Genes Dev 2000, 14(2):147-151.

23. Griffiths RL, Hidalgo A: Prospero maintains the mitotic potential of glial precursors enabling them to respond to neurons. EMBO J 2004, 23(12):2440-2450.

24. Liu TH, Li L, Vaessin H: Transcription of the Drosophila CKI gene dacapo is regulated by a modular array of cis-regulatory sequences. Mech Dev 2002, 112(1-2):25-36

25. Choksi SP, Southall TD, Bossing T, Edoff $K$, de Wit E, Fischer BE, van Steensel B, Micklem G, Brand AH: Prospero acts as a binary switch between self-renewal and differentiation in Drosophila neural stem cells. Dev Cell 2006, 11(6):775-789.

26. Eisen MB, Spellman PT, Brown PO, Botstein D: Cluster analysis and display of genome-wide expression patterns. Proc Natl Acad Sci USA 1998, 95(25):14863-14868.

27. Zeeberg BR, Feng W, Wang G, Wang MD, Fojo AT, Sunshine M, Narasimhan S, Kane DW, Reinhold WC, Lababidi S, et al: GoMiner: a resource for biological interpretation of genomic and proteomic data. Genome Biol 2003, 4(4):R28.

28. Lawrence CE, F AS, Boguski MS, Liu JS, Neuwald AF, Wootton JC: Detecting subtle sequence signals: a Gibbs sampling strategy for multiple alignment. Science 1993, 262(5131):208-214.

29. Crooks GE, Hon G, Chandonia JM, Brenner SE: WebLogo: a sequence logo generator. Genome Res 2004, 14(6):1188-1190.

30. Cook T, Pichaud F, Sonneville R, Papatsenko D, Desplan C: Distinction between color photoreceptor cell fates is controlled by Prospero in Drosophila. Dev Cell 2003, 4(6):853-864.

31. Garcia-Alonso L, Romani S, Jimenez F: The EGF and FGF receptors mediate neuroglian function to control growth cone decisions during sensory axon guidance in Drosophila. Neuron 2000, 28(3):741-752.

32. Hassan BA, Bermingham NA, He Y, Sun $Y$, Jan $Y N$, Zoghbi HY, Bellen HJ: atonal regulates neurite arborization but does not act as a proneural gene in the Drosophila brain. Neuron 2000, 25(3):549-561.

33. Srahna M, Leyssen $M$, Choi CM, Fradkin LG, Noordermeer JN, Hassan BA: A signaling network for patterning of neuronal connectivity in the Drosophila brain. PLOS Biol 2006, 4(11):e348.

34. Marek KW, Ng N, Fetter R, Smolik S, Goodman CS, Davis GW: A genetic analysis of synaptic development: pre- and postsynaptic dCBP control transmitter release at the Drosophila NMJ. Neuron 2000, 25(3):537-547.

35. Kraut R, Menon K, Zinn K: A gain-of-function screen for genes controlling motor axon guidance and synaptogenesis in Drosophila. Curr Biol 2001, 11(6):417-430

36. Ang LH, Kim J, Stepensky V, Hing H: Dock and Pak regulate olfactory axon pathfinding in Drosophila. Development 2003, 130(7):1307-1316.

37. Laviolette MJ, Nunes P, Peyre JB, Aigaki T, Stewart BA: A genetic screen for suppressors of Drosophila NSF2 neuromuscular junction overgrowth. Genetics 2005, 170(2):779-792.

38. Learte AR, Forero MG, Hidalgo A: Gliatrophic and gliatropic roles of PVF/ PVR signaling during axon guidance. Glia 2008, 56(2):164-176.

39. Marin EC, Watts RJ, Tanaka NK, Ito K, Luo L: Developmentally programmed remodeling of the Drosophila olfactory circuit. Dev 2005, 132(4):725-737.

40. Speese SD, Trotta N, Rodesch CK, Aravamudan B, Broadie K: The ubiquitin proteasome system acutely regulates presynaptic protein turnover and synaptic efficacy. Curr Biol 2003, 13(11):899-910.
41. Haas KF, Miller SL, Friedman DB, Broadie K: The ubiquitin-proteasome system postsynaptically regulates glutamatergic synaptic function. $\mathrm{Mol}$ Cell Neurosci 2007, 35(1):64-75.

42. Arquier N, Bourouis M, Colombani J, Léopold P: Drosophila Lk6 kinase controls phosphorylation of eukaryotic translation initiation factor $4 \mathrm{E}$ and promotes normal growth and development. Curr Biol 2005, 15(1):19-23.

43. Reiling JH, Doepfner KT, Hafen E, Stocker H: Diet-dependent effects of the Drosophila Mnk1/Mnk2 homolog Lk6 on growth via elF4E. Curr Biol 2005 15(1):24-30.

44. Juhasz G, Puskas LG, Komonyi O, Erdi B, Maroy P, Neufeld TP, Sass M: Gene expression profiling identifies FKBP39 as an inhibitor of autophagy in larval Drosophila fat body. Cell Death Differ 2007, 14(6):1181-1190.

45. Yue X, Song W, Zhang W, Chen L, Xi Z, Xin Z, Jiang X: Mitochondrially localized EGFR is subjected to autophagic regulation and implicated in cell survival. Autophagy 2008, 4(5):701-703.

46. Rafel N, Milán M: Notch signalling coordinates tissue growth and wing fate specification in Drosophila. Development 2008, 135(24):3995-4001.

47. Adamson AL, Shearn A: Molecular genetic analysis of Drosophila ash2, a member of the trithorax group required for imaginal disc pattern formation. Genetics 1996, 144(2):621-633.

48. Bose A, Kahali B, Zhang S, Lin JM, Allada R, Karandikar U, Bidwai AP: Drosophila CK2 regulates lateral-inhibition during eye and bristle development. Mech Dev 2006, 123(9):649-664

49. Kanuka H, Kuranaga E, Takemoto K, Hiratou T, Okano H, Miura M: Drosophila caspase transduces Shaggy/GSK-3beta kinase activity in neural precursor development. EMBO J 2005, 24(21):3793-3806.

50. Mollereau B, Domingos PM: Photoreceptor differentiation in Drosophila: from immature neurons to functional photoreceptors. Dev Dyn 2005, 232(3):585-592.

51. Fichelson P, Audibert A, Simon F, Gho M: Cell cycle and cell-fate determination in Drosophila neural cell lineages. Trends Genet 2005, 21(7):413-420.

52. Lai EC, Orgogozo V: A hidden program in Drosophila peripheral neurogenesis revealed: fundamental principles underlying sensory organ diversity. Dev Biol 2004, 269(1):1-17.

53. Gao FB, Brenman JE, Jan LY, Jan YN: Genes regulating dendritic outgrowth, branching, and routing in Drosophila. Genes Dev 1999, 13(19):2549-2561.

54. Morey M, Yee SK, Herman T, Nern A, Blanco E, Zipursky S: Coordinate control of synaptic-layer specificity and rhodopsins in photoreceptor neurons. Nature 2008, 456:795-799.

55. Williams DW, Shepherd D: Persistent larval sensory neurons in adult Drosophila melanogaster. J Neurobiol 1999, 39(2):275-286.

56. Tissot M, Stocker RF: Metamorphosis in drosophila and other insects: the fate of neurons throughout the stages. Prog Neurobiol 2000, 62(1):89-111.

57. Zhao T, Gu T, Rice HC, McAdams KL, Roark KM, Lawson K, Gauthier SA, Reagan $\mathrm{KL}$, Hewes RS: A Drosophila gain-of-function screen for candidate genes involved in steroid-dependent neuroendocrine cell remodeling. Genetics 2008, 178(2):883-901.

58. Grewal SS: Insulin/TOR signaling in growth and homeostasis: a view from the fly world. Int J Biochem Cell Biol 2009, 41:1006-1010.

59. Jünger MA, Rintelen F, Stocker $H$, Wasserman JD, Végh $M$, Radimerski $T$, Greenberg ME, Hafen E: The Drosophila forkhead transcription factor FOXO mediates the reduction in cell number associated with reduced insulin signaling. J Biol 2003, 2(3):20.

60. Scott RC, Schuldiner O, Neufeld TP: Role and regulation of starvationinduced autophagy in the Drosophila fat body. Dev Cell 2004, 7(2):167-178.

61. Jacinto $\mathrm{E}, \mathrm{Hall} \mathrm{MN}$ : Tor signalling in bugs, brain and brawn. Nat Rev Mol Cell Biol 2003, 4(2):117-126.

62. Teleman AA, Hietakangas V, Sayadian AC, Cohen SM: Nutritional control of protein biosynthetic capacity by insulin via Myc in Drosophila. Cell Metab 2008, 7(1):21-32.

63. Colombani J, Raisin S, Pantalacci S, Radimerski T, Montagne J, Leopold P: A nutrient sensor mechanism controls Drosophila growth. Cell 2003, 114(6):739-749.

64. Guertin DA, Guntur KV, Bell GW, Thoreen CC, Sabatini DM: Functional genomics identifies TOR-regulated genes that control growth and division. Curr Biol 2006, 16(10):958-970. 
65. Shilo BZ: Regulating the dynamics of EGF receptor signaling in space and time. Development 2005, 132(18):4017-4027.

66. Okano H, Hayashi S, Tanimura T, Sawamoto K, Yoshikawa S, Watanabe J, Iwasak iM, Hirose S, Mikoshiba K, Montell C: Regulation of Drosophila neural development by a putative secreted protein. Differentiation 1992, 52(1):1-11.

67. Mayer $U$, Nusslein-Volhard C: A group of genes required for pattern formation in the ventral ectoderm of the Drosophila embryo. Genes Dev 1988, 2(11):1496-1511.

68. Sun H, Oakley B: Development of anterior gustatory epithelia in the palate and tongue requires epidermal growth factor receptor. Dev Biol 2002, 242(1):31-43.

69. Kauffmann RC, Li S, Gallagher PA, Zhang J, Carthew RW: Ras1 signaling and transcriptional competence in the R7 cell of Drosophila. Genes Dev 1996, 10(17):2167-2178.

70. Xu J, Xin S, Du W: Drosophila Chk2 is required for DNA damagemediated cell cycle arrest and apoptosis. FEBS lett 2001, 508(3):394-398.

71. Hayashi T, Xu C, Carthew RW: Cell-type-specific transcription of prospero is controlled by combinatorial signaling in the Drosophila eye. Development 2008, 135(16):2787-2796.

72. Grosjean Y, Balakireva M, Dartevelle L, Ferveur JF: PGal4 excision reveals the pleiotropic effects of Voila, a Drosophila locus that affects development and courtship behaviour. Genet Res 2001, 77(3):239-250.

73. Dudoit S, Fridlyand J: A prediction-based resampling method for estimating the number of clusters in a dataset. genome Biol 2002. 3(7):31-21.

74. Shaffer AL, Rosenwald A, Hurt EM, Giltnane JM, Lam LT, Pickeral OK, Staudt LM: Signatures of the immune response. Immunity 2001, 15(3):375-385.

75. Golub TR, Slonim DK, Tamayo P, Huard C, Gaasenbeek M, Mesirov JP, Coller H, Loh ML, Downing JR, Caligiuri MA, et al: Molecular classification of cancer: class discovery and class prediction by gene expression monitoring. Science 1999, 286(5439):531-537.

76. Tusher VG, Tibshirani R, Chu G: Significance analysis of microarrays applied to the ionizing radiation response. Proc Natl Acad Sci USA 2001, 98(9):5116-5121.

77. Ashburner M, Ball CA, Blake JA, Botstein D, Butler H, Cherry JM, Davis AP, Dolinski K, Dwight SS, Eppig JT, et al: Gene ontology: tool for the unification of biology. The Gene Ontology Consortium. Nat Genet 2000, 25(1):25-29.

doi:10.1186/1471-2164-11-47

Cite this article as: Guenin et al:: Expression profiling of prospero in the Drosophila larval chemosensory organ: Between growth and outgrowth. BMC Genomics 2010 11:47.

\section{Submit your next manuscript to BioMed Central and take full advantage of:}

- Convenient online submission

- Thorough peer review

- No space constraints or color figure charges

- Immediate publication on acceptance

- Inclusion in PubMed, CAS, Scopus and Google Scholar

- Research which is freely available for redistribution

Submit your manuscript at www.biomedcentral.com/submit
Biomed Central 